\title{
Egg-dumping behaviour in the seed beetle Acanthoscelides obtectus (Coleoptera: Chrysomelidae: Bruchinae) selected for early and late reproduction
}

\author{
Darka ŠEŠLIJA ${ }^{1}$, BilJana STOJKOVIĆ ${ }^{1,2}$, Branka TUCIĆ $^{1}$ and NiKola TUCIĆ ${ }^{1,2 *}$ \\ ${ }^{1}$ Department of Evolutionary Biology, Institute for Biological Research "Siniša Stanković”, Blvd Despota Stefana 142, \\ 11060 Belgrade, Serbia; e-mail: ntucic@ibiss.bg.ac.rs \\ ${ }^{2}$ Faculty of Biology, University of Belgrade, Studentski trg 16, 11000 Belgrade, Serbia
}

Key words. Chrysomelidae, Bruchinae, Acanthoscelides obtectus, egg-dumping, selection, longevity

\begin{abstract}
In the present study the egg dumping behaviour in short (E)- and long (L)-lived lines of the seed beetle Acanthoscelides obtectus was analyzed. Females of the short-lived E line exhibited substantially higher egg dumping than long-lived L line females. We hypothesize that, since cessation of egg dumping enhances longevity, non-dumping females were selectively favoured in the L regime. Our study also produced evidence that the selection regime affected the male's ability to influence female egg-dumping behaviour. The females mated to males from the lines that were selected for extended longevity and of which the females exhibited little egg-dumping dumped fewer eggs. We suggest that in the L selection regime, where offspring produced at the end of the females' reproductive period were recruited to the next generation, selection operated against those males that stimulated female oviposition in the absence of seeds. This is the first study to provide evidence that selection for long-lived insects results in the reduced potency of male seminal products to stimulate female oviposition.
\end{abstract}

\section{INTRODUCTION}

Females of many herbivorous and parasitic insects often display considerable plasticity in their oviposition behaviour in response to resource quality and/or availability (Papaj, 2000, 2005; Jervis et al., 2005). For example, some insect females respond to host deprivation by retarding egg maturation (Sadehi \& Gilbert, 2000) or postponing egg laying (Åsman \& Ekborn, 2006). Moreover, in many taxa, females deposit eggs on substrates unsuitable for larval growth (Messina \& Slade, 1999; Parsons \& Credland, 2003; Roberts \& Schmidt, 2004; Wang \& Horng, 2004). This form of oviposition behaviour is termed "egg-dumping" (Engelmann, 1970; Wilson \& Hill, 1989). Because there is a trade-off between present reproduction and survival or future reproduction (Stearns, 1992), egg-dumping may be a maladaptive involuntary response of mated females that cannot prevent oocyte maturation when hosts are absent (the egg-load hypothesis; Wilson \& Hill, 1989; Roberts \& Schmidt, 2004). Alternatively, egg-dumping could be an adaptive response to a shortage of hosts if it increases a female's overall efficiency in maturing eggs and ovipositing (the egg-maturation hypothesis, Wang \& Horng, 2004). Papaj (2000) and Hougardy et al. (2005) argue that if cessation of oviposition disrupts oocyte maturation, egg-dumping females may have an advantage over non-dumping ones since they can immediately lay eggs when hosts become available.

However, it is noteworthy that egg-dumping varies within a species. For example, when deprived of a host females of the bruchid seed beetle Callosobruchus macu- latus from Africa dumped markedly more eggs than those from Asia, most of which did not dump eggs. Messina et al. (2007) suggest that different responses to host availability might be determined and shaped by larval competition. According to these authors, in Asian populations larval competition is minimized by the females laying equal numbers of eggs on each seed and avoiding those that already bear eggs or larvae. This is achieved by reducing oviposition in response to a reduction in the number and quality of hosts, i.e. "it may be more profitable for a female to retain eggs and continue to search for unoccupied hosts than to lay eggs on occupied seeds" (Messina et al., 2007. p. 265). In African populations, however, several adults usually emerge from the same seed. In such highly competitive conditions the larva that hatches from the first egg laid is more likely to survive as the first larva to enter a seed has a competitive advantage over succeeding larvae (Thanthianga \& Michel, 1987). Females in Africa might have evolved less effective mechanisms for egg retention and thus be more prone to dump eggs.

An analogous pattern of inter-population variation with regard to egg-dumping behaviour is reported in another bruchid seed beetle - Acanthoscelides obtectus. Huignard \& Biemont $(1978,1979)$ report that females of this species from high-altitude populations, where the environment is more variable and unpredictable, do not lay in the absence of host seeds. In contrast, at low altitude, where hosts are continuously available, the presence of suitable hosts is not essential for inducing oogenesis although it does stimulate oocyte maturation.

\footnotetext{
* Corresponding author.
} 
A number of studies also report high variation in the number of eggs dumped by host-deprived females within populations of both these bruchid species (Parsons \& Credland, 2003; Cheng et al., 2008 and references therein). Messina et al. (2007) carried out bidirectional selection for high and low egg dumping to determine whether this trait has an additive genetic component that can respond to selection within the African population of C. maculatus. Artificial selection elicited a response in both directions with deprived females from the dumper line dumping more than twice as many eggs as females from the non-dumper line. It is important to note that the selection for low egg dumping is accompanied by a longer pre-adult developmental time, which is a potential cost for females that retain eggs when seeds are absent. However, because developmental time and longevity are positively genetically correlated in insects (Šešlija \& Tucić, 2003 and references therein), an extended longevity of the non-dumper lines is an expected response of selection for low egg dumping.

If the observed association between egg dumping and longevity really reflect pleiotropic effects of genes, as suggested by Messina et al. (2007), it may be expected that selection for longevity will be accompanied by concomitant changes in egg dumping. However, we must keep in mind that "correlated responses to selection depend on the details of pleiotropic effects rather than on genetic correlation, and that because of this, correlated responses to selection can be more variable (and less predictable) than direct responses to selection" (Gromko, 1995 , p. 691). In addition, the trade-off recorded in the selection for dumping behaviour may also be attributable to linkage disequilibrium between the genes that affect pre-adult developmental time and those that affect longevity. Therefore, it is almost impossible to generalize about the genetic correlations between traits, except by selecting for one trait and recording the response in the other and vice versa (Tucić et al., 1998). In the present study we test whether selection for altering the age at physiological maturity, which directly favours short- or long-lived females, results in the changes in egg-dumping behaviour predicted by Messina et al. (2007).

Here we used replicated lines of the seed beetle Acanthoscelides obtectus selected for reproduction early (E) or late (L) in life for over 150 generations. In the E selection regime, offspring were recruited to the next generations during the first two days of adult life, whereas in the $\mathrm{L}$ selection regime, the recruitment occurred from day 10 until death. Previous studies indicate that relative to the $\mathrm{E}$ lines the L lines have a reduced early fecundity, increased body weight, elevated late life fecundity and prolonged life-span (Tucić et al., 1997, 1998). It is important to note that in the $\mathrm{L}$ lines the period between eclosion and the onset of oviposition is longer than in the $\mathrm{E}$ lines (Tucić et al., 2004), indicating that the traits under selection coincide with the age of female's physiological maturity.

A major component of this study concerns the experimental test of the relationship between egg dumping and female longevity in this seed beetle. If there is a causal link between female longevity and egg dumping, as indicated by the C. maculatus study (Messina et al., 2007), females should dump eggs significantly more in the $\mathrm{E}$ than $\mathrm{L}$ lines. The results obtained in the present study accord with this prediction.

A previous study indicates that the males of the seed beetle $A$. obtectus play an important role in shaping the longevity of their mates (Šešlija et al., 2008). An analysis of the effects of males on female longevity in Petri dishes with no beans revealed that the control females that mated with $\mathrm{E}$ males dumped more eggs relative to those mated from the long-lived L line. Although it is well-known that insect male seminal fluids contain gonadotropic substances that influence the reproductive performance of females (see e.g. Arnqvist \& Rowe, 2005 and reference therein), their role in egg-dumping is unknown. By using reciprocal crosses between the $\mathrm{L}$ and $\mathrm{E}$ lines as well as by mating $\mathrm{E}$ and $\mathrm{L}$ males with control females, we have shown that $\mathrm{E}$ line males selected for fast senescence stimulate higher egg-dumping by females, irrespective of their origin, relative to males selected for slow senescence. Therefore, we hypothesize that males that transfer seminal substances that decrease egg-dumping in their mates will be favoured by the $\mathrm{L}$ selection regime. The observation of male effects on female egg dumping is novel and suggests complicated fertility/longevity interactions between the sexes in seed beetles.

\section{MATERIAL AND METHODS}

\section{Life history and experimental conditions}

The seed beetle, Acanthoscelides obtectus (Coleoptera: Chrysomelidae: Bruchinae) is a cosmopolitan pest of stored legumes. The primary host of these weevils is the common bean, Phaseolus vulgaris. Populations of A. obtectus are most commonly detected in stores of dried legumes; their life cycle appears well adapted for reproduction in a storage environment. Larval development takes place in plant seeds and adults emerge at the final moult. A. obtectus males are protandrous. The oviposition behaviour of A. obtectus differs in a number of ways from that of other bruchids. At the beginning of adult life, virgin females produce about 30 mature eggs complete with chorions, which accumulate in the lateral oviducts, after which oogenesis stops (Huignard, 1975). Oogenesis only starts again in the presence of stimulatory factors, such as host plant and mating. A number of studies record that $A$. obtectus females do not lay eggs in the absence of seeds (Huignard, 1976; Biemont, 1979; Huignard et al., 1986) or females deposit significantly fewer eggs in the absence of a host (Sander \& Pankanin, 1973; Parsons \& Credland, 2003). There are no significant differences in the number of eggs laid by females either kept alone or in the continued presence of males (Parsons \& Credland, 2003). Females do not re-mate until a few days after their initial mating (Huignard, 1974). In A. obtectus, as in a number of other insect species, there is a transfer of male secretions from the spermatophore into the female haemolymph (Das et al., 1980).

This beetle is aphagous as an adult, and females at emergence contain sufficient energy to develop and lay eggs without feeding. All experiments reported here were performed in a dark incubator at about $30^{\circ} \mathrm{C}$ and $70 \%$ relative humidity. All seeds were brought from one source and were frozen before use in the experiments. No food or water was offered to experimental adults. 
A



B



Fig. 1. Mean ( \pm SE) body weight (A) and longevity (B) of A. obtectus females and males of the $\mathrm{E}$ and $\mathrm{L}$ lines.

\section{Experimental lines}

The seed beetles used in this study were obtained from lines that were selected for reproduction in either early (E) or late-life (L). There was four replicates of each selection regime. All selection lines were originally derived from a large base population (B) cultured in the laboratory since 1986, which consisted of about 5,000 individuals in each generation. This population was produced by mass-mating equal numbers of adults collected from three local populations of $A$. obtectus in the vicinity of Belgrade, Serbia. In the absence of beans B females mated to B males deposited $3.71 \pm 0.57$ eggs during their entire life-span (unpubl. data).

The following summarizes the selection procedures used to maintain the $\mathrm{E}$ and L selected lines (details are given in Tucić et al., 1996).

Through the course of selection for early reproduction females and males were kept together with beans and allowed to mate and reproduce freely for $48 \mathrm{~h}$ following emergence after which the adults were removed. In each generation about 300-500 individuals per replicate were used to produce the next generation. This treatment gave rise to beetles with both enhanced fitness during early life and a shorter life-span. In the present study we used beetles from E lines selected for 211 generations.

L lines were obtained from beetles selected for 150 generations. Each generation over 1,000 females and males in the $\mathrm{L}$ lines were kept together in about 10 separate vials (i.e. about 100 individuals per vial) without beans and allowed to mate from emergence until death. Since beans were introduced at day 10 , no eggs laid prior to this day contributed to the next generation (for details see Tucić et al., 1996). Consequently, these lines underwent selection for late fitness. Adults of both sexes from the $\mathrm{L}$ lines lived longer than $\mathrm{E}$ lines. The other life history traits that differed in the $\mathrm{E}$ and $\mathrm{L}$ lines were egg-to-adult viability $(\mathrm{L}>\mathrm{E})$, pre-adult developmental time $(\mathrm{L}>\mathrm{E})$, body weight $(L>E)$, early female fecundity $(E>L)$ and late female fecundity $(\mathrm{L}>\mathrm{E})$.

\section{Experimental design}

All experiments described below were done using four-way crosses within each selection regime. These crosses were obtained by crossing the $F_{1} s$ of different pairs of replicate lines within each selection regime, that is, for example, $\left(\mathrm{E}_{1} \times \mathrm{E}_{2}\right) \times$ $\left(E_{3} \times E_{4}\right)$, where the subscript number refer to specific replicate line. The outcrossing of replicate lines should have removed the effect of inbreeding depression and diminished any epistatic interaction among genes originating during the long-term selection due to Wahlund's effect or mutation pressure. In addition, the first and second generations of crosses were made from 1-day old beetles allowed to mate and reproduce during their entire life-span. This procedure ensured that selected lines (i.e. their crosses) pass two generations under relaxed selection in a standard rearing regime.

Stock cultures were inspected several times per day and newly emerged females and males were collected within $2 \mathrm{~h}$. Beetles were immediately weighed and virgin females without egg-laying experience and males were placed individually in empty, 3.5-mm Petri dishes. One hundred beetle pairs were isolated per mating group. We investigated female egg-dumping behaviour in the following mating groups: $\mathrm{E}(q) \times \mathrm{E}\left(\delta^{\star}\right) ; \mathrm{E}(q)$


$(q) \times \mathrm{L}(\delta)$. The number of eggs laid and dead females and males were counted every day. This procedure provided estimates of lifetime realized fecundity, age-specific fecundity and female longevity in the absence of seeds.

\section{Data analyses}

All data analyses were performed using SAS (SAS Institute, 2003). Since body size was positively correlated with both female fecundity and longevity, the appropriate ANOVA models (following examination of normality and homogeneity of variance assumption) were applied after removing the linear effect of body size on these traits. This was done by using the



Fig. 2. Realized fecundity (mean $\pm \mathrm{SE}$ ) of host-deprived females from the $\mathrm{E}$ and $\mathrm{L}$ lines which were crossed with males from either the same or the other line. First letters denote females. $\mathrm{N}=100$ females per cross. 




Fig. 3. Frequency distribution of the percentages of females from the $\mathrm{E}$ and $\mathrm{L}$ lines, which were crossed with males from either the same or the other line, that dumped different numbers of eggs during the course of their lives when deprived of hosts. First letters denote females.

residuals from the body weight vs. fecundity or longevity linear regression analyses. Proportional data (percentages of dumper females) were compared using a G test (Sokal \& Rohlf, 1995). Because several tests were conducted on these data, probabilities were recalculated using the sequential Bonferroni test to adjust for multiple comparisons (Rice, 1989).

\section{RESULTS}

The mean body weight and longevity of both sexes in the $\mathrm{E}$ and $\mathrm{L}$ lines are given in Fig. 1. These results accord with earlier findings (Tucić et al., 1996, 1997, 1998). As shown by two-way ANOVA, the wet weight of females and males was greater in the $\mathrm{L}$ than the $\mathrm{E}$ lines $\left(\mathrm{F}_{1,399}=\right.$ 482.90, $P<0.001)$. Males were lighter than females $\left(\mathrm{F}_{1,399}\right.$ $=482.90, P<0.001)$ in both selected lines. We did not find a significant line $\times$ sex interaction $\left(\mathrm{F}_{1,399}=3.49, P>\right.$ 0.05). A comparison of the lifespan data (Fig. 1) after removing the effect of body size showed that $\mathrm{L}$ beetles lived longer than $\mathrm{E}$ beetles $\left(\mathrm{F}_{1,398}=1157.90, P<0.0001\right)$ and females outlived males $\left(\mathrm{F}_{1,398}=599.81, P<0.0001\right)$ in both lines. Interestingly, females in the $\mathrm{E}$ lines lived for about $24 \%$ longer than males, whereas the L females outlived males from their own experimental lines by about $42 \%$. This pattern in female-male longevity results in a significant line $\times$ sex interaction in a two-way ANOVA $\left(\mathrm{F}_{1,398}=198.6390, P<0.0001\right)$. Keeping in mind that $A$. obtectus females seem to benefit from water and/or nutrients received from ejaculates (Tucić et al., 1996; Šešlija et al., 2009), it can be argued that L females, which were not fed during the adult stage, were selected to rely on male ejaculates to a greater extent than E females. Therefore, the shorter life-span of males from the L lines compared to the E males may be a consequence of evolution associated with female exploitation of the male-derived nuptial gift. This conclusion is in the line with the prediction that when resources are scarce, male reproductive investment in offspring, together with the associated costs


Fig. 4. (A) Fecundity (mean number of eggs \pm SE) and (B) frequency distribution of the percentage of B females mated with either $\mathrm{E}$ or $\mathrm{L}$ males that dumped different numbers of eggs during their lifetime when deprived of hosts. $\mathrm{N}=100$ females per cross. 
of mating, can exceed the costs experienced by females (Hall et al., 2009).

When mated with males from their own line, the hostdeprived $\mathrm{E}$ females (i.e. $\mathrm{E} \times \mathrm{E}$ ) dumped significantly more eggs over their lifetimes than $\mathrm{L}$ females from the $\mathrm{L}$ $\times \mathrm{L}$ crosses (Fig. 2; $\mathrm{F}_{1,199}=7.25, P<0.01$ ). Moreover, $67 \%$ of these $\mathrm{L}$ females and $53 \%$ of those from $\mathrm{E} \times \mathrm{E}$ crosses died without dumping a single egg (Fig. 3), which indicates that the long-lived L line contained significantly more non-dumper females than the short-lived $\mathrm{E}$ line $(\mathrm{G}=$ $4.10 ; P<0.05)$. However, when $\mathrm{E}$ females were mated to $\mathrm{L}$ males their lifetime mean fecundity when deprived of hosts was only about 0.8 eggs (Fig. 2), which was significantly less than females in the $\mathrm{E} \times \mathrm{E}$ crosses (mean $=2.8$; $\left.\mathrm{F}_{1,199}=9.58, P<0.01\right)$. Also, the percentage of nondumpers in the $\mathrm{E} \times \mathrm{L}$ crosses was substantially greater $(86 \%)$ than in the $\mathrm{E} \times \mathrm{E}$ crosses $(\mathrm{G}=26.76 ; P<0.001)$. In contrast, the comparison of the $\mathrm{L} \times \mathrm{L}$ and $\mathrm{L} \times \mathrm{E}$ crosses showed that mating with $\mathrm{E}$ males increased the mean number of dumped eggs $\left(3.4\right.$ vs. $1.6 ; \mathrm{F}_{1,198}=4.17, P$ $<0.05)$ and reduced the percentage of non-dumping $\mathrm{L}$ females $(52 \%$ vs. $67 \%$; $\mathrm{G}=4.28, P<0.05)$. Female body weight appears to be unrelated to the egg-dumping tendency, since there were no significant weight differences between dumpers and non-dumpers within both the $\mathrm{E}$ and $\mathrm{L}$ lines (mean body weights for dumpers and nondumpers were 6.4 vs. 6.2 and 4.7 vs. 4.3 within the $\mathrm{L} \times \mathrm{L}$ and $\mathrm{E} \times \mathrm{E}$ crosses, respectively and dumping effect from two way ANOVA was $\mathrm{F}_{1,199}=1.67, P>0.05$ ).

The $\mathrm{E}$ and $\mathrm{L}$ males had a similar effect on egg-dumping when mated with females from the base (B) population (Fig. 4). Over their lifetime, B females mated with E males dumped on average 5.5 eggs, whereas those mated with $\mathrm{L}$ males dumped 3.1 eggs per female $\left(\mathrm{F}_{1,197}=5.29, P\right.$ $<0.05)$. In addition, the percentage of non-dumping $\mathrm{B}$ females was significantly higher in crosses with $L$ than $E$ males (63\% and 48\%, respectively; $\mathrm{G}=4.57, P<0.05$ ). Thus, the $\mathrm{E}$ males relative to the $\mathrm{L}$ males significantly increased the percentage of females dumping eggs. These results indicate that males can affect egg-dumping by females, possibly by transferring substances during copulation.

\section{DISCUSSION}

In the present study females from the short-lived E lines exhibited substantially higher egg dumping than the longlived L line females. Although female body weight appears to be unrelated to the egg-dumping tendency within both lines, the $\mathrm{E}$ females were smaller than $\mathrm{L}$ females suggesting that the smaller E females might have a lower capacity to store oocytes, as suggested by Wilson \& Hill (1989). However, it seems that the changes in egg dumping recorded result primarily from selection for short- and long-lived individuals.

In terms of selection among females with respect to their reproductive behaviour, these selection regimes differ dramatically. In contrast to E females, which were selected for early reproduction in the absence of seeds, $\mathrm{L}$ females had to survive in vials for 10 days without host seeds in order to produce offspring. Having in mind these differences between selection regimes there are two possible explanations for the observed levels of egg-dumping in the $\mathrm{E}$ and $\mathrm{L}$ lines. First, it can be argued that $\mathrm{E}$ females, which were provided with beans at the very start of their interaction with males, had little opportunity to dump eggs and thus did not experience selection against this maladaptive behaviour. Second, the lines could be different in the egg-dumping levels because non-dumping females were favoured in the L selection regime. In other words, females that laid eggs prior to the introduction of beans had a shorter life, as previously shown for C. maculatus (Credland \& Wright, 1989; Messina \& Fry, 2003). Also, their egg production after day 10 should be smaller than that of non-dumping females.

One way to test these two possibilities is to compare the levels of egg-dumping in the two selected lines with those recorded in the base population (B). Although the data for the $\mathrm{B} \times \mathrm{B}$ crosses is not presented in this study, using unpublished estimates of egg-dumping in the base population (see Materials and methods) the following pattern was revealed (the groups were tested for significance using the Tukey test $)$ : $[(\mathrm{B} \times \mathrm{B}$; mean $=3.71)=(\mathrm{E} \times \mathrm{E}$; mean $=2.78)]>[(\mathrm{L} \times \mathrm{L} ;$ mean $=1.57)]$. Therefore, $\mathrm{a}$ more likely explanation is that non-dumping females were favoured by the $\mathrm{L}$ selection regime, i.e. the increase in female longevity in the L lines was achieved, at least in part, by selection for low egg-dumping.

Moreover, an additional factor promoting non-dumping behaviour in the $\mathrm{L}$ line is the requirement of $A$. obtectus females for a host stimulant to achieve maximum oogenesis (Pouzat, 1978; Huignard et al., 1986). In the absence of seeds in the $\mathrm{L}$ selection regime, as shown in previous studies (e.g. Tucić et al., 2004), the age of physiological maturity was markedly postponed. If mortality and reproduction patterns are inextricably linked to rates of adult maturation, as predicted by Williams' theory of ageing (1957), then an increase in adult lifespan is an expected outcome (Šešlija \& Tucić, 2008). Although Williams' theory of ageing does not predict that the rates of adult maturation are also linked to the pre-adult developmental time, it was longer in the $\mathrm{L}$ line than in the $\mathrm{E}$ line. Peculiar to bruchid beetles, the divergence in the age of physiological maturity between $\mathrm{L}$ and $\mathrm{E}$ lines is also accompanied by a divergence in egg dumping behaviour. Even though Messina et al. (2007) did not determine the age of physiological maturity in their low and high egg dumping selected lines, the correlated responses recorded in other two traits paralleled those observed in our L and E lines. Indeed, as suggested by Messina et al. (2007) such pleiotropic effects in bruchid insects "may reflect joint dependence on circadian-clock genes and other endogenous-timing genes" (p. 265). Besides regulation of daily rhythmic behaviours, these genes are implicated in regulation of the timing of non-circadian phenomena, such as developmental time, the frequency of male courtship and duration of copulation in Drosophila (Beaver \& Giebultowitcz, 2004) and, perhaps, as suggested by 
Messina et al. (2007), in dumping behaviour in bruchid beetles.

The effect of males on the life history traits of females are well documented in many insect species (reviewed in Vahed, 2007). In the seed beetles, males can reduce female longevity, mediated, for instance, through the seminal compounds with toxic side-effects (Das et al., 1980), but can also prolong female longevity by providing them with water and/or nutrients contained in the male ejaculate (Maklakov et al., 2005; Šešlija et al., 2008). The stimulation of oviposition by proteins transferred from males has also been recorded (Das et al., 1980). In the present study we found evidence that male selection regime significantly affects egg-dumping by females. Females dumped fewer eggs when mated to males from lines that were selected for lower rates of senescence in which the females usually exhibited low incidence of egg-dumping. These results are the first evidence that selection for long-lived insects could lead to the reduced potency of male seminal products to stimulate female oviposition.

Reduced oviposition is adaptive to female in the absence of host seeds. To refrain from laying eggs could improve a female's survival and, if she continues to search for hosts, the chance of producing progeny. However, it is less clear what benefits are for males if they produce seminal products with such physiological activities. A reduction in female oviposition following copulation does not appear to be advantageous in terms of male-to-male competition. This holds only if, after successful copulation, paternity is certain. However, for males in the L lines it may not be advantageous for them to stimulate female oviposition because these females laid only a few eggs when seeds become available after 10 days and, as a result, "inducing males" would produce fewer offspring than non inducing males. Thus, it seems that $\mathrm{L}$ regime also selects males that do not stimulate females to lay eggs immediately after mating. Interestingly, L males enhance female fecundity only if the females can use oviposition sites immediately after mating (Šešlija et al., 2008). Therefore, it seems that in $A$. obtectus the effects of males on female oviposition behaviour could be changed in accordance with environmental context, i.e. presence or absence of host seeds.

ACKNOWLEDGEMENTS. This study was supported by the Ministry of Science and Technological Development of Serbia, project No. 143033. Three anonymous referees provided helpful comments and suggestions.

\section{REFERENCES}

Arnqvist G. \& Rowe L. 2005: Sexual Conflict. Princeton University Press, Princeton, $356 \mathrm{pp}$.

ÅsMAN K. \& EKBORN B. 2006: Responses of ovipositing moths to host plant deprivation: life history aspects and implications for intercropping. Agric. For. Entomol. 8: 213-219.

Beaver M. \& Giebultowicz J.M. 2004: Regulation of copulation duration by period and timeless in Drosophila melanogaster. Curr. Biol. 14: 1492-1497.
Biemont J.C. 1979: Vitellogenesis in Acanthoscelides obtectus (Coleoptera: Bruchidae). I. Oocyte development and vitellogenin in a European strain. Int. J. Invert. Reprod. 1: 221-232.

Cheng C.-W., Yang R.-L., Cheng I.-C. \& Horng S.-B. 2008: Egg-dumping: a strategy for host range expansion in Callosobruchus maculatus (Coleoptera: Bruchidae). Ann. Entomol. Soc. Am. 101: 950-954.

Credland P.F. \& Wright A.W. 1989: Factors affecting female fecundity in the cowpea seed beetle Callosobruchus maculatus (Coleoptera: Bruchidae). J. Stor. Prod. Res. 25: 125-136.

Das A.K., Huignard J., Barbier M. \& Quesneau-Thierry A. 1980: Isolation of two paragonial substances deposited into the spermatophores of Acanthoscelides obtectus (Coleoptera: Bruchidae). Experientia 36: 918-920.

Engelmann F. 1970: The Physiology of Insect Reproduction. Pergamon Press, Oxford, 307 pp.

GromKo M.H. 1995: Unpredictability of correlated response to selection: pleiotropy and sampling interact. Evolution 49: 685-693.

Hall M.D., Bussiere L.F. \& Brooks R. 2009: Diet-dependent female evolution influences male lifespan in a nuptial feeding inscect. J. Evol. Biol. 22: 873-881.

Hougardy E., Bezemer T.M. \& Mills J.N. 2005: Effects of host deprivation and egg expenditure on the reproductive capacity of Matrus ridibundus, and introduced parasitoid for the biological control of the codling moth in California. Biol. Control 33: 96-106.

Huignard J. 1974: Influence de la copulation sur la fonction reproductrice femelle sur Acanthoscelides obtectus. I. Copulation et spermatophore. Ann. Sci. Nat. 16: 361-434.

HuignaRd J. 1975: Influence de la copulation sur la fonction reproductrice femelle sur Acanthoscelides obtectus. II. Influence de la copulation sur la fonction reproductrice femelle sur Acanthoscelides obtectus. Ann. Sci. Nat. 17: 1-16.

Huignard J. 1976: Interactions between the host-plant and mating upon the reproductive cycle of Acanthoscelides obtectus females (Coleoptera, Bruchidae). Symp. Biol. Hung. 16: $101-108$.

Huignard J. \& Biemont J.C. 1978: Comparison of four populations of Acanthoscelides obtectus (Coleoptera Bruchidae) from different Colombian ecosystems: assay of interpretation. Oecologia 35: 307-318.

Huignard J. \& Biemont J.C. 1979: Vitellogenesis in Acanthoscelides obtectus (Coleoptera: Bruchidae). II. The conditions of vitellogenesis in a strain from Colombia. Comparative study and adaptive significance. Int. J. Invert. Reprod. 1: 233-244.

Huignard J., Thibout E. \& Biemont J.C. 1986: Synchronisation of the reproductive cycle of some phytophagous insects by their host plant. Its adaptive significance. In Porchet M., Andries C.J. \& Dhainaut A. (eds): Advances in Invertebrate Reproduction. Elsevier, Amsterdam, pp. 425-432.

Jervis M.A., Boggs C.L. \& Ferns P.N. 2005: Egg maturation strategy and its associated trade-offs: a synthesis focusing on Lepidoptera. Ecol. Entomol. 30: 359-375.

Maklakov A.A., Kremer N. \& Arnquist G. 2005: Adaptive male effects on female ageing in seed beetles. Proc. R. Soc. 272: 2485-2489.

Messina F.J. \& FRY J.D. 2003: Environment-dependent reversal of a life history trade-off in the seed beetle Callosobruchus maculatus. J. Evol. Biol. 16: 501-509.

Messina F.J. \& Slade A.F. 1999: Expression of a life-history trade-off in a seed beetle depends on environmental context. Physiol. Entomol. 24: 358-363. 
Messina F.J., Morrey J.L. \& Mendenhall M. 2007: Why do host-deprived cowpea weevil "dump" their eggs? Physiol. Entomol. 32: 259-267.

Papaj D.R. 2000: Ovarian dynamics and host use. Annu. Rev. Entomol. 45: 423-448.

PAPAJ D.R. 2005: Ovarian dynamics in relation to host quality in the walnut-infesting fly, Rhagoletis juglandis. Funct. Ecol. 19: 396-404.

Parsons D.M.H. \& CRedland P.F. 2003: Determination of oviposition in Acanthoscelides obtectus, a nonconformist bruchids. Physiol. Entomol. 28: 221-231.

PouzAT J. 1978: Host plant chemosensory influence on oogenesis in the bean weevil, Acanthoscelides obtectus (Coleoptera: Bruchidae). Entomol. Exp. Appl. 24: 401-408.

RICE W.R. 1989: Analyzing tables of statistical tests. Evolution 43: $223-225$.

RoBerts H.L.S. \& Schmidt O. 2004: Lifetime egg maturation by host-deprived Ventura canescens. J. Insect Physiol. 50: 195-202.

SADEghi H. \& Gilbert F. 2000: The effect of egg load and host deprivation on oviposition behaviour in aphidophagous hoverflies. Ecol. Entomol. 25: 101-108.

SANDER H. \& PANKANIN M. 1973: Effect of the presence of food on egg laying by Acanthoscelides obtectus (Say) (Coleoptera, Bruchidae). Pol. Pis. Entomol. 43: 811-817.

ŠEšLIJA D. \& Tucić N. 2003: Selection for developmental time in bean weevil (Acanthoscelides obtectus): correlated responses for other life history traits and genetic architecture of line differentiation. Entomol. Exp. Appl. 106: 19-35.

ŠEŠLIJA D. \& TuCIĆ N. 2008: The genetic architecture of extended life span in the seed beetle Acanthoscelides obtectus (Coleoptera: Bruchidae). Eur. J. Entomol. 105: 553-560.

Š́ŠLIJA D. , MAREČKo I. \& TuCIĆ N. 2008: Sexual selection and senescence: do seeds beetle (Acanthoscelides obtectus, Bruchidae, Coleoptera) shape the longevity of their mates? $J$. Zool. Syst. Evol. Res. 46: 323-330.

Šešlija D., Lazarevic J., Janković B. \& Tucić N. 2009: Mating behavior on the seed beetle Acanthoscelides obtectus selected for early and late reproduction. Behav. Ecol. 20: 547-552.
SoKal R.R. \& RohlF F.J. 1995: Biometry. W.H. Freeman, New York, $880 \mathrm{pp}$.

SteARns S.C. 1992: The Evolution of Life Histories. Oxford University Press, Oxford, $535 \mathrm{pp}$.

Thanthianga C. \& Mitchell R.M. 1987: Vibrations mediate prudent resource exploitation by competing larvae of the bruchid bean weevil Callosobruchus maculatus. Entomol. Exp. Appl. 44: 15-21.

Tucić N., Gliksman I., Šešlija D., Milanović D., Mikuljanac S. \& STолкоvić O. 1996: Laboratory evolution of longevity in the bean weevil (Acanthoscelides obtectus). J. Evol. Biol. 9: 485-503.

Tucić N., Stojković O., Gliksman I., Milanović D. \& Šešlija D. 1997: Laboratory evolution of life-history traits in the bean weevil (Acanthoscelides obtectus): the effects of densitydependent and age-specific selection. Evolution 51: 1896-1909.

Tucić N., Gliksman I., Šešlija D., Stojković O. \& Milanović D. 1998: Laboratory evolution of life-history traits in the bean weevil (Acanthoscelides obtectus): the effects of selection on developmental time in populations with different previous history. Evolution 52: 1713-1725.

Tucić N., ŠešliJa D. \& STAnKović V. 2004: The short-term and long-term effects of parental age in the bean weevil (Acanthoscelides obtectus). Evol. Ecol. 18: 187-201.

VAHED K. 2007: All that glister is not gold: sensory bias, sexual conflict and nuptial feeding in insects and spiders. Ethology 113: $105-127$.

Wang M.-H. \& Horng S.-B. 2004: Egg dumping and life history strategy of Callosobruchus maculatus. Physiol. Entomol. 29: $26-31$.

WiLLIAMS G.C. 1957: Pleiotropy, natural selection, and the evolution of senescence. Evolution 11: 398-411.

WiLson K. \& HiLl L. 1989: Factors affecting egg maturation in the bean weevil Callosobruchus maculatus. Physiol. Entomol. 14: 115-126.

Received May 7, 2009; revised and accepted July 7, 2009 